Article

\title{
Chemical Compositions of the Volatile Oils and Antibacterial Screening of Solvent Extract from Downy Lavender
}

\author{
Chang Ha Park ${ }^{1,+}$, Ye Eun Park ${ }^{1,+}$, Hyeon Ji Yeo ${ }^{1}$, Se Won Chun ${ }^{1}$, Thanislas Bastin Baskar ${ }^{1}$, \\ Soon Sung Lim ${ }^{2}$ and Sang Un Park ${ }^{1, *}$ \\ 1 Department of Crop Science, Chungnam National University, 99 Daehak-ro, Yuseong-gu, \\ Daejeon 34134, Korea; parkch804@gmail.com (C.H.P.); yeney1996@cnu.ac.kr (Y.E.P.); \\ gusw17627@gmail.com (H.J.Y.); seaw613@cnu.ac.kr (S.W.C.); bastinbt20@yahoo.com (T.B.B.) \\ 2 Department of Food and Nutrition and Institute of Natural Medicine, Hallym University, \\ Chuncheon 200-702, Korea; limss@hallym.ac.kr \\ * Correspondence: supark@cnu.ac.kr; Tel.: +82-42-821-5730; Fax: +82-42-822-2631 \\ + These authors contributed equally to this work.
}

Received: 1 March 2019; Accepted: 16 April 2019; Published: 19 April 2019

\begin{abstract}
The discovery of a new species exhibiting more effective antibacterial properties is necessary because of the demand on Lavandula species, which continues to increase in a variety of industries. Lavandula pubescens might be a good alternative, as it exhibits strong antibacterial activity. In this study, the chemical composition of the essential oils from different organs (flowers, leaves, stems, and roots) of L. pubescens was identified using gas chromatography-mass spectrometry. Furthermore, the antimicrobial activities of different solvent extracts (methanol, ethanol, diethyl ether, hexane, and ethyl acetate) and different organ (flower, leaf, stem, and root) extracts of L. pubescens were evaluated. Only the ethyl acetate extracts of L. pubescens exhibited antibacterial activity against all bacterial strains tested, including Staphylococcus haemolyticus, Escherichia coli (KF 918342), Aeromonas hydrophila (KCTC 12487), E. coli (ATCC 35150), Cronobacter sakazakii (ATCC 29544), and Aeromonas salmonicida (KACC 15136). In particular, the extracts exhibited significant activity against $S$. haemolyticus. Ethyl acetate extract of the leaf exhibited the best activity against all bacterial strains. This study provides valuable information on the chemical compositions in essential oils and antimicrobial properties of L. pubescens.
\end{abstract}

Keywords: Lavandula pubescens; essential oil; antibacterial activity

\section{Introduction}

Lavandula pubescens, also known as downy lavender, is an aromatic flowering plant belonging to the Lamiaceae family. Lavandula, consisting of approximately 39 known species, has been largely cultivated as ornamental plants for gardens and scenery use. This perennial plant is widely distributed in the Mediterranean, North Africa, Southwest Asia, western Iran, and eastern India [1]. The widely used and cultivated lavender species are Lavandula angustifolia, Lavandula officinalis, Lavandula latifolia, and Lavandula vera. Lavandula pubescens is a newly discovered species of lavender, which occurs in the Mediterranean. In recent years, the plants have been extensively studied as resources for medicine and aromatic products and used largely for their medicinal potentials, because these plants contain a number of bioactive compounds that act against human and plant pathogens [2], as well as compounds with various activities and properties [3].

Presently, Lavandula is widely studied because of its commercial use in the fragrance industry [4,5]. The plants have also been used as antibacterial, sedative, and antiviral agents in the pharmaceutical 
industries [6]. The essential oil of Lavandula species is presently used in food manufacturing industries for flavoring. Lavandula essential oil contains monoterpenes and is used in soaps, shampoos, mouthwashes, and household cleaners [7]. Previous studies reported that plant essential oils have natural preservative properties against food-borne microorganisms causing many infectious diseases in humans and widely contaminating meat and meat products [8] as well as fish-borne zoonotic parasites causing human anisakidosis $[9,10]$. Furthermore, these essential oils can improve prolongation of the shelf-life of perishable food products. Thus, Lavandula essential oil has been used in the food industry $[11,12]$.

Essential oils, also called volatile or ethereal oils, are defined as an aromatic hydrophobic liquid, including a broad diversity of volatile compounds, and are derived from plant materials, such as the roots, stem, flowers, leaves, buds, seeds, and fruits [13]. Lavender essential oils have been used in complementary medicines, in cosmetics, or as food additives for centuries, because these oils have been traditionally regarded as antibacterial, antifungal, carminative, sedative, anti-inflammatory, and anti-depressive agents [14]. The chemical compounds in the oils, conferring such a biological property, can be classified into two main fractions: A volatile fraction that accounts for $90-95 \%$ of the whole oil and contains hydrocarbons (terpenes, sesquiterpenes, and diterpenes) and oxygenated derivatives generated from hydrocarbons containing phenols, aldehydes, esters, alcohol, oxides, and alcohols. The second non-volatile fraction forms $5-10 \%$ of the whole oil and includes waxes, hydrocarbons, sterols, fatty acids, carotenoids, psoralens, coumarins, and flavonoids $[15,16]$. The chemical composition varies greatly depending largely on species or extraction methods [17].

The antimicrobial activity of Lavandula has been widely studied [18-20]. Lavender plants have been used as a relaxant in aromatherapy [21,22]. Antioxidant and antiviral activities of Lavandula essential oil have been reported [23-25]. Therefore, this study aims to provide information on volatile constituents of in the essential oils from different organs (flowers, leaves, stems, and roots) of L. pubescens using gas chromatography-mass spectrometry (GC-MS) and the antibacterial activities of different plant parts of L. pubescens.

\section{Materials and Methods}

\subsection{Chemicals}

Ethanol (EtOH), methanol (MeOH), hexane, and ethyl acetate (EA) were purchased from Samchun Pure Chemical, Pyeongtaek, Korea. Diethyl ether (DE) and dimethyl sulfoxide (DMSO) were purchased from Sigma-Aldrich, Yongin, Korea. Luria-Bertani (LB) broth and streptomycin sulfate was purchased from MB cell, Seoul, Korea.

\subsection{Plant Material and Extraction}

The root, stem, leaf, and flower of L. pubescens were collected from the green house of Chungnam National University (Figure 1). The plants were washed under running tap water and dried under shade for three weeks. The extraction was performed according to the previous study [26]. The dried plants were then powdered using mortar and pestle and extracted with different solvents, including ethanol, methanol, hexane, ethyl acetate, and diethyl ether, respectively. The powdered sample (10 g) was soaked in $50 \mathrm{~mL}$ of the different solvents and incubated in an ultrasound bath (JAC-4020, KODO, Technical Research Co., Ltd., Hwaseong, Korea) for 1 day. The filtrate was then evaporated using a rotary vacuum evaporator (Laborota 4000, Heidolph Instruments Inc., Schwabach, Germany) and stored at $4{ }^{\circ} \mathrm{C}$ until needed for the antibacterial analysis. For screening of the different plant organs, the roots, stems, leaves, and flowers were collected, powdered, and dissolved in ethyl acetate for 1 day, after which each extract was collected and evaporated, as described above, and dissolved in the same solvent for further use. 


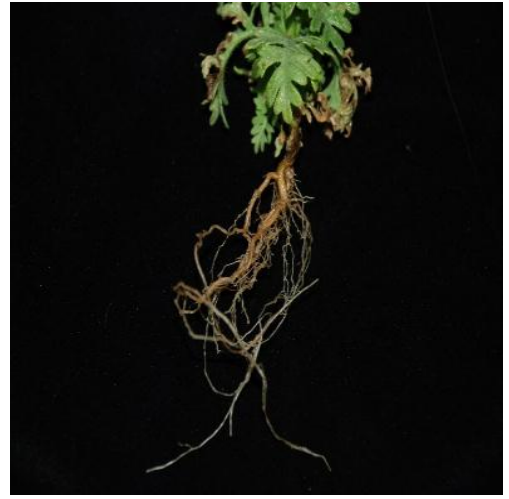

(a)

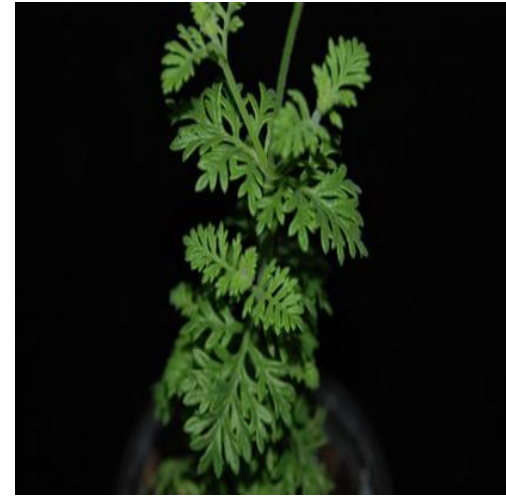

(b)

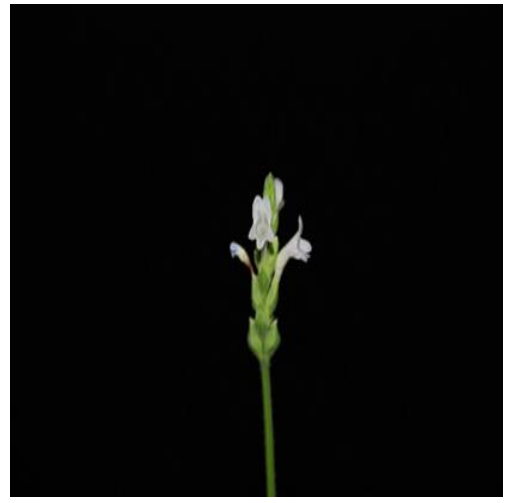

(c)

Figure 1. Photographs of the root (a), leaf and stem (b), and flower (c) of Lavandula pubescens.

\subsection{Bacterial Strains and Cultivation}

Six bacterial strains were used in this study: Escherichia coli (KF 918342), Staphylococcus haemolyticus (KCTC 3341), Aeromonas hydrophila (KCTC 12487), Escherichia coli (ATCC 35150), Cronobacter sakazakii (ATCC 29544), and Aeromonas salmonicida (KACC 15136). These strains were collected from the medicine department of Chungnam National University. The bacterial strains (Escherichia coli (KF 918342), Staphylococcus haemolyticus (KCTC 3341), Escherichia coli (ATCC 35150), Cronobacter sakazakii (ATCC 29544), and Aeromonas salmonicida (KACC 15136)) were cultured at $37^{\circ} \mathrm{C}$ and the strain (Aeromonas hydrophila (KCTC 12487)) was cultured at $30^{\circ} \mathrm{C}$ for $18-24 \mathrm{~h}$ in a $50 \mathrm{~mL}$ sample of LB broth prepared in a $250 \mathrm{~mL}$ conical flask medium placed on an orbital shaker. Optical density (OD) measurement was performed at $600 \mathrm{~nm}$ using a UV-1800 spectrophotometer (Shimadzu Corp., Kyoto, Japan). The culture flask was inoculated at $0.1 \mathrm{OD}_{600}$ (optical density at $600 \mathrm{~nm}$ ) with freshly prepared LB medium under the same culture conditions. The mid log phase bacterial cultures were used for the antibacterial studies. Staphylococcus haemolyticus (KCTC 3341) was the only gram-positive bacteria used in this study; all others were gram-negative bacteria.

\subsection{GC-MS Analysis of L. pubescens}

Volatile compounds were extracted and analyzed using a previously reported GC-MS method [27]. GC-MS analysis was performed on a 7820A GC/5977E MSD (Agilent, Santa Clara, CA, USA) with an HP-5 (30 m $\times 0.25 \mathrm{~mm}$ ID, film thickness $0.25 \mu \mathrm{m}$ ) fused-silica capillary column (Agilent, USA). Helium was used as the carrier gas at a flow rate of $1.0 \mathrm{~mL} / \mathrm{min}$. For GC-MS detection, an electron ionization system, with system energy of $70 \mathrm{eV}$, trap current of $250 \mu \mathrm{A}$, and an ion source temperature of $200{ }^{\circ} \mathrm{C}$, was used. The oven temperature program was the same as that described for GC, and injections were used in the splitless mode. The column temperature was maintained at $35^{\circ} \mathrm{C}$ for $2 \mathrm{~min}$ and programmed as follows: Increase from 50 to $250{ }^{\circ} \mathrm{C}$ at a rate of $10^{\circ} \mathrm{C} / \mathrm{min}$ and hold at $250{ }^{\circ} \mathrm{C}$ for $10 \mathrm{~min}$. Fresh samples of each plant part $(2.0 \mathrm{~g}$ ) were placed in a $15 \mathrm{~mL}$ thermostatted vial that has a rubber septum. During the SPME extraction procedure, the SPME fiber was introduced for $12 \mathrm{~h}$ into the thermostatted vial (RT). For this analysis, a $1 \mathrm{~cm}, 50 / 30 \mu \mathrm{m}$ polydimethylsiloxane/divinylbenzene/carboxen-coated fiber was used. The fiber was conditioned in a GC injection port for $1 \mathrm{~min}$ prior to use. The absorbed component was injected into a gas chromatograph by desorption at $250^{\circ} \mathrm{C}$ for $2 \mathrm{~min}$ in the injector (splitless mode).

\subsection{Antibacterial Screening}

\subsubsection{Disk Diffusion Method}

A $0.1 \mathrm{OD}_{600}$ of the different overnight bacterial cultures was swabbed on a $25 \mathrm{~mL}$ LB agar plate. Whatman disk was then placed on the plates. A $30 \mu \mathrm{L}$ sample of different solvent extracts of L. pubescens was added to the sterilized disk (Whatman No. 1 paper, $6 \mathrm{~mm}$ diameter) and incubated overnight 
at $37^{\circ} \mathrm{C}$. For screening of the different plant organs, the powdered samples were dissolved in ethyl acetate, and the resulting extract was added to the Whatman disk. Streptomycin $(250 \mu \mathrm{g} / \mathrm{mL})$ was used as the standard antibacterial agent. The experiment was performed in triplicate.

\subsubsection{Minimum Inhibitory Concentration}

The minimum inhibitory concentration (MIC) of the L. pubescens extracts was established according to the method of Abdullah Al-Dhabi et al. [28] by using 96-well plates. A $1 \mathrm{mg} / \mathrm{mL}$ extract was dissolved in water with $2 \%$ DMSO. The initial extract concentration was $50 \mu \mathrm{L}$ crude extract, which was then serially diluted two-fold $(1.5625$ to $50 \mu \mathrm{L})$. Each well had $100 \mu \mathrm{L}$ of LB broth. Then, extracts were added at the concentrations described above. A $5 \mu \mathrm{L}$ suspension containing $10^{8} \mathrm{CFU} / \mathrm{mL}$ of each of the six bacterial strains was added to the 96-well plate and incubated at $37^{\circ} \mathrm{C}$ for $17 \mathrm{~h}$. After the incubation time, the minimum inhibitor concentration was determined by the lowest visible growth in LB broth. The experiment was performed in triplicate.

\section{Results}

\subsection{GC-MS Analysis of L. pubescens}

Chemical composition of the essential oils of different organs of L. pubescens, such as the roots, stems, leaves, and flowers, were identified by GC-MS analysis. Most of the essential oils from different organs were characterized by the dominant presence of terpenes, including monoterpenes, diterpenes, and sesquiterpenes (Table 1). The oil from the leaves contained nine monoterpenes-neo-allo-ocimene (21.91\%), $p$-cymenene (18.15\%), terpinolene (3.31\%), isothymol methyl ether $(2.8 \%), m$-cymene $(2.1 \%)$, $\gamma$-terpinene (1.64\%), carvacrol $(0.78 \%)$, 2,5,5-trimethyl-1,3,6-heptatriene $(0.76 \%)$, and trans-3-caren-2-ol $(0.76 \%)$; nine sesquiterpenes-alloaromadendrene $(2.45 \%)$, caryophyllene $(2.45 \%), \beta$-bisabolene $(0.96 \%)$, $\alpha$-muurolene $(0.17 \%),(-)$ - $\beta$-elemene $(0.16 \%), \beta$-ylangene $(0.13 \%), \beta$-guaiene $(0.11 \%), \alpha$-calacorene $(0.11 \%)$, and acoradien $(0.07 \%)$; and one diterpene-jolkinol D $(0.16 \%)$, comprising $94.62 \%$ of the total leaf-derived essential oil.

The essential oil from the stems contained 10 monoterpenes-neo-allo-ocimene (15.68\%), isothymol methyl ether (13.35\%), $\gamma$-terpinene $(11.09 \%)$, terpinolene $(10.17 \%), p$-cymenene $(7.66 \%), m$-cymene (2.89\%), carvacrol (2.54\%), trans-3-caren-2-ol (2.51\%), 2,5,5-trimethyl-1,3,6-heptatriene (1.83\%), and 4-terpinyl acetate $(1.34 \%)$; and 10 sesquiterpenes-caryophyllene $(9.97 \%), \beta$-bisabolene $(3.52 \%)$, $\beta$-ylangene $(1.46 \%)$, longifolene $(1.04 \%), \alpha$-cubebene $(0.65 \%), \beta$-eudesmene $(0.58 \%), \alpha$-ylangene $(0.38 \%)$, caryophyllene oxide $(0.33 \%)$, aromandendrene $(0.11 \%)$, and acoradien $(0.08 \%)$, comprising $99.47 \%$ of the total stem-derived essential oil.

The essential oil from the roots contained 14 monoterpenes-m-cymene (49\%), $\alpha$-terpinene $(4.22 \%), 4$-terpinyl acetate $(3.73 \%),(-)$-4-terpineol $(3.05 \%), p$-xylene $(2.46 \%), \gamma$-terpinene $(2.28 \%)$, D-limonene $(2.0 \%), p$-cymenene $(1.99 \%)$, terpinolene $(1.90 \%), \alpha$-terpinene $(1.57 \%)$, carvacrol $(0.41 \%)$ neo-allo-ocimene $(0.36 \%)$, trans-3-caren-2-ol $(0.33 \%)$, and isothymol methyl ether $(0.35 \%)$; and 21 sesquiterpenes-(-)-calamenene $(6.33 \%), \alpha$-gurjunene $(3.30 \%), \alpha$-copaene $(1.54 \%), \beta$-eudesmene $(1.21 \%), \alpha$-bergamotene $(1.00 \%)$, caryophyllene $(0.91 \%), \delta$-cadinene $(0.88 \%), \alpha$-muurolene $(0.86 \%)$, cyclosativene $(0.81 \%),(-)$ - $\beta$-elemene $(0.66 \%), \beta$-copaene $(0.61 \%), \gamma$-cadinene $(0.48 \%), \alpha$-calacorene $(0.48 \%), \alpha$-cubebene $(0.43 \%), \beta$-guaiene $(0.42 \%), \alpha$-ylangene $(0.41 \%)$, acoradien $(0.38 \%)$, caryophyllene oxide $(0.19 \%)$, alloaromadendrene $(0.16 \%),(+)$-ledene $(0.14 \%)$, and aromandendrene $(0.07 \%)$, comprising $99.03 \%$ of the total root-derived essential oil.

The essential oil from flowers contained 13 monoterpenes-4-terpinyl acetate $(16.99 \%)$, p-cymenene (11.66\%), neo-allo-ocimene (8.55\%), 1,3,5,5-tetramethyl-1,3-cyclohexadiene (2.95\%), 2,5,5-trimethyl-1,3,6-heptatriene (2.75\%), $\gamma$-terpinene (2.39\%), $m$-cymene (1.31\%), trans-3-caren-2-ol $(1.12 \%), \alpha$-terpinene $(0.87 \%)$, carvacrol $(0.27 \%), p$-xylene $(0.15 \%)$, and $\mathrm{D}$-limonene $(0.08 \%)$; and 5 sesquiterpenes-longifolene $(2.2 \%), \beta$-bisabolene $(0.72 \%), \alpha$-bergamotene $(0.36 \%)$, caryophyllene $(0.23 \%)$, and acoradien $(0.07 \%)$, comprising $99.44 \%$ of the total flower-derived oil. 
Table 1. Compounds identified in the different organs of Lavandula pubescens using gas chromatographymass spectrometry (GC-MS).

\begin{tabular}{|c|c|c|c|c|c|}
\hline \multirow{2}{*}{ Volatile Compound } & \multicolumn{5}{|c|}{ Peak Area $(\%)$} \\
\hline & RT $^{1}$ & Leaf & Stem & Flower & Root \\
\hline$p$-Xylene & 5.22 & $\mathrm{ND}^{2}$ & ND & 0.15 & 2.46 \\
\hline D-Limonene & 6.8 & ND & ND & 0.08 & 2 \\
\hline$\gamma$-Terpinene & 7.37 & 1.64 & 11.09 & 2.39 & 2.28 \\
\hline$\alpha$-Terpinene & 7.49 & ND & ND & 0.33 & 4.22 \\
\hline 1,3,5,5-Tetramethyl-1,3-cyclohexadiene & 7.6 & ND & ND & 2.95 & ND \\
\hline$m$-Cymene & 7.67 & 2.1 & 2.89 & 1.31 & 49 \\
\hline 2,5,5-Trimethyl-1,3,6-heptatriene & 7.81 & 0.76 & 1.83 & 2.75 & ND \\
\hline 4-Terpinyl acetate & 8.19 & ND & 1.34 & 16.99 & 3.73 \\
\hline Terpinolene & 8.67 & 3.31 & 10.17 & ND & 1.9 \\
\hline$p$-Cymenene & 8.74 & 18.15 & 7.66 & 11.66 & 1.99 \\
\hline trans-3-Caren-2-ol & 9.11 & 0.76 & 2.51 & 1.12 & 0.33 \\
\hline (-)-4-Terpineol & 10.13 & ND & ND & ND & 3.05 \\
\hline Neo-allo-ocimene & 9.32 & 21.91 & 15.68 & 8.55 & 0.36 \\
\hline$\alpha$-Terpinene & 10.35 & ND & ND & 0.54 & 1.57 \\
\hline Isothymol methyl ether & 11.06 & 2.8 & 13.35 & ND & 0.35 \\
\hline Carvacrol & 11.97 & 0.78 & 2.54 & 0.27 & 0.41 \\
\hline$\alpha$-Cubebene & 12.58 & ND & 0.65 & ND & 0.43 \\
\hline$\alpha$-Ylangene & 12.9 & ND & 0.38 & ND & 0.41 \\
\hline$\alpha$-Copaene & 12.96 & ND & ND & ND & 1.54 \\
\hline$(-)-\beta$-Elemene & 13.15 & 0.16 & ND & ND & 0.66 \\
\hline Alloaromadendrene & 13.22 & 2.45 & ND & ND & 0.16 \\
\hline$(+)$-Ledene & 13.41 & ND & ND & ND & 0.14 \\
\hline Longifolene & 13.46 & ND & 1.04 & 2.2 & ND \\
\hline Caryophyllene & 13.58 & 2.45 & 9.97 & 0.23 & 0.91 \\
\hline$\beta$-Ylangene & 13.67 & 0.13 & 1.46 & ND & ND \\
\hline$\alpha$-Bergamotene & 13.7 & ND & ND & 0.36 & 1 \\
\hline Aromandendrene & 13.82 & ND & 0.11 & ND & 0.07 \\
\hline Caryophyllene oxide & 13.94 & ND & 0.33 & ND & 0.19 \\
\hline Acoradien & 14.02 & 0.07 & 0.08 & 0.07 & 0.38 \\
\hline$\delta$-Cadinene & 14.23 & ND & ND & ND & 0.88 \\
\hline Cyclosativene & 14.25 & ND & ND & ND & 0.81 \\
\hline$\alpha$-Muurolene & 14.3 & 0.17 & ND & ND & 0.86 \\
\hline$\beta$-Copaene & 14.35 & ND & ND & ND & 0.61 \\
\hline$\beta$-Eudesmene & 14.45 & ND & 0.58 & ND & 1.21 \\
\hline$\alpha$-Gurjunene & 14.53 & ND & ND & ND & 3.3 \\
\hline$\beta$-Bisabolene & 14.6 & 0.96 & 3.52 & 0.72 & ND \\
\hline$\gamma$-Cadinene & 14.74 & ND & ND & ND & 0.48 \\
\hline (-)-Calamenene & 14.85 & ND & ND & ND & 6.33 \\
\hline$\beta$-Guaiene & 15.03 & 0.11 & ND & ND & 0.42 \\
\hline$\alpha$-Calacorene & 15.11 & 0.11 & ND & ND & 0.48 \\
\hline Jolkinol D & 20.22 & 0.16 & ND & ND & ND \\
\hline 1,3,5,7-Cyclooctatetraene & 5.57 & 0.85 & ND & 0.37 & ND \\
\hline (3E)-2,7-Dimethyl-3-octen-5-yen & 6.05 & ND & 0.14 & 0.18 & 2.35 \\
\hline 5,6-Dimethylene-1-cyclooctene & 6.62 & 0.48 & ND & 0.02 & ND \\
\hline Benzaldehyde & 6.79 & 1.22 & ND & 0.12 & ND \\
\hline 1,2,3,4,5-Pentamethylcyclopentadiene & 6.88 & 0.63 & ND & 0.85 & ND \\
\hline 2,5-Dimethyl-3-methylene-5-heptadiene & 7.15 & ND & 1.04 & 2.42 & ND \\
\hline$\alpha$-Cumene hydroperoxide & 7.71 & 1.45 & 2.05 & 0.13 & ND \\
\hline 6-Methyl-5-(1-methylethylidene)-6,8-nonadien-2-one & 7.72 & 8.25 & 2.66 & 6.47 & ND \\
\hline (3Z)-2,7-Dimethyl-3-octen-5-yne & 8.04 & 0.55 & ND & ND & ND \\
\hline 1,3-Dimethyl-1,5-cyclooctadiene & 8.41 & 0.31 & ND & 19.76 & ND \\
\hline 1-Methyl6-isopropylidene & 8.6 & 6.18 & 2.51 & 14.94 & ND \\
\hline 4-(1,5-Dihydro-2,4,3-benzodioxaborepin-3-yl) benzoic acid & 9.04 & 0.36 & ND & ND & ND \\
\hline $\begin{array}{l}\text { 1-Amino-2-(4-chlorobenzoyl)-6,7,8,9-tetrahydro-5- } \\
\text { methylthieno[2,3-c]isoquinoline }\end{array}$ & 9.62 & 0.65 & 2.87 & ND & 0.61 \\
\hline Naphthalene & 10.31 & 0.39 & ND & ND & ND \\
\hline $\begin{array}{l}\text { 6-Isopropenyl-3-(methoxymethoxy)-3-methyl- } \\
\text { 1-cyclohexene }\end{array}$ & 10.34 & 0.62 & ND & ND & ND \\
\hline
\end{tabular}


Table 1. Cont.

\begin{tabular}{lccccc}
\hline \multicolumn{1}{c}{ Volatile Compound } & \multicolumn{5}{c}{ Peak Area (\%) } \\
\cline { 2 - 6 } & RT $^{\mathbf{1}}$ & Leaf & Stem & Flower & Root \\
\hline Benzothiazole & 10.98 & 0.38 & ND & 1.42 & ND \\
3,5,7-Trimethoxy-2-(4-methoxyphenyl)-4H-chromen- 4-one & 12.09 & 0.35 & 0.83 & ND & 0.18 \\
8-Valerolactone & 14.06 & 0.44 & ND & 0.09 & 0.24 \\
2,6-Di-tert-butylbenzoquinone & 14.13 & 0.27 & ND & ND & 0.38 \\
4,4,5,6-Tetramethyl-1,3-oxazinane-2-thione & 16.23 & 3.06 & ND & ND & ND \\
2-(3-Acetoxy-4,4,10,13,14-pentamethyl- & & & & \\
2,3,4,5,6,7,10,11,12,13,14,15,16,17-tetradecahydro-1H- & 16.34 & 0.26 & ND & ND & 0.09 \\
cyclopenta[a]phenanthren-17-yl)-propanoic acid & & & & ND \\
2,6-Di-tert-butylhydroquinone & 16.74 & 0.65 & ND & ND & ND \\
3,5-Bis(tert-butyl)-4-hydroxy-propiophenon & 17.79 & 0.21 & ND & ND & ND \\
(6-tert-Butyl-1,1-dimethyl-2,3-dihydro-1H-inden- & 17.88 & 0.5 & ND & ND & ND \\
4-yl)acetic acid & 18.2 & 5.18 & ND & ND & ND \\
2,4,6-Tri-tert-butylphenol & 18.95 & 0.52 & ND & ND & ND \\
1-(3,5-Di-tert-butyl-4-hydroxyphenyl)propan-1-one & 19.23 & 0.29 & 0.2 & ND & ND \\
3,3,3',3',5,5,5',5'-Octamethyl-1,1'-bi(1-cyclohexen-1yl) & 19.49 & 0.14 & ND & ND & 0.15 \\
3-Deoxyestradiol & 20.74 & 1.48 & ND & ND & ND \\
1-Nitrosopyrrolidine & 28.36 & ND & ND & ND & 0.1 \\
3-Hydroxyspirost-8-en-11-one & & 94.65 & 99.48 & 99.44 & 99.02 \\
\hline Total identified (\%) & &
\end{tabular}

${ }^{1}$ RT, Retention time. ${ }^{2}$ ND, Not detected.

\subsection{Antimicrobial Screening of L. pubescens}

The antimicrobial screening of L. pubescens was performed using five different organic solvents. The ethyl acetate extract showed more antimicrobial activity against the six pathogenic bacteria because the disk diffusion method revealed that the ethyl acetate extract produced higher activity than that by the other organic solvents. In particular, L. pubescens possessed significant activity against S. haemolyticus, followed by E. coli (KF 918342), A. hydrophila (KCTC 12487), E. coli (ATCC 35150), C. sakazakii (ATCC 29544), and A. salmonicida (KACC 15136) (Table 2). Therefore, ethyl acetate was used for further studies on antimicrobial activities of L. pubescens because it had the strongest activity against all the bacteria. The antibacterial activity against bacterial pathogens using different plant organ extracts in agar plates is shown in Figure 2. The leaf extract exhibited the most powerful antibacterial activity against all bacterial strains, followed by the flower and stem extracts. On the other hand, the roots did not exhibit antimicrobial activity (Table 3).

Table 2. Antibacterial activity of Lavandula pubescens using extracts with different solvents. Each value is the average of three trials \pm standard deviation.

\begin{tabular}{ccccccc}
\hline \multirow{2}{*}{ Strains } & \multicolumn{5}{c}{ Zone of Inhibition(mm) from L. pubescens Extracts } \\
\cline { 2 - 6 } & $\mathbf{M e O H}^{\mathbf{1}}$ & EtOH $^{\mathbf{2}}$ & DE $^{\mathbf{3}}$ & EA $^{\mathbf{4}}$ & Hexane & Streptomycin \\
\hline $\begin{array}{c}\text { Escherichia coli } \\
\text { (KF 918342) }\end{array}$ & $\mathrm{NA}^{5}$ & $\mathrm{NA}$ & $\mathrm{NA}$ & $21.3 \pm 0.6$ & $\mathrm{NA}$ & $27.6 \pm 0.6$ \\
$\begin{array}{c}\text { Staphylococcus haemolyticus } \\
\text { Aeromonas hydrophila }\end{array}$ & $\mathrm{NA}$ & $\mathrm{NA}$ & $\mathrm{NA}$ & $24.0 \pm 0.0$ & $\mathrm{NA}$ & $26.3 \pm 0.6$ \\
$\begin{array}{c}\text { Escherichia coli } \\
\text { (ATCC 35150) }\end{array}$ & $\mathrm{NA}$ & $\mathrm{NA}$ & $\mathrm{NA}$ & $21.0 \pm 1.0$ & $\mathrm{NA}$ & $27.0 \pm 0.0$ \\
$\begin{array}{c}\text { Cronobacter sakazakii } \\
\text { Aeromonas salmonicida }\end{array}$ & $\mathrm{NA}$ & $\mathrm{NA}$ & $\mathrm{NA}$ & $20.6 \pm 1.1$ & $\mathrm{NA}$ & $28.3 \pm 0.6$ \\
\hline
\end{tabular}

${ }^{1} \mathrm{MeOH}$, methanol. ${ }^{2} \mathrm{EtOH}$, ethanol. ${ }^{3} \mathrm{DE}$, di ethyl ether. ${ }^{4} \mathrm{EA}$, ethyl acetate. ${ }^{5} \mathrm{NA}$, no activity. 


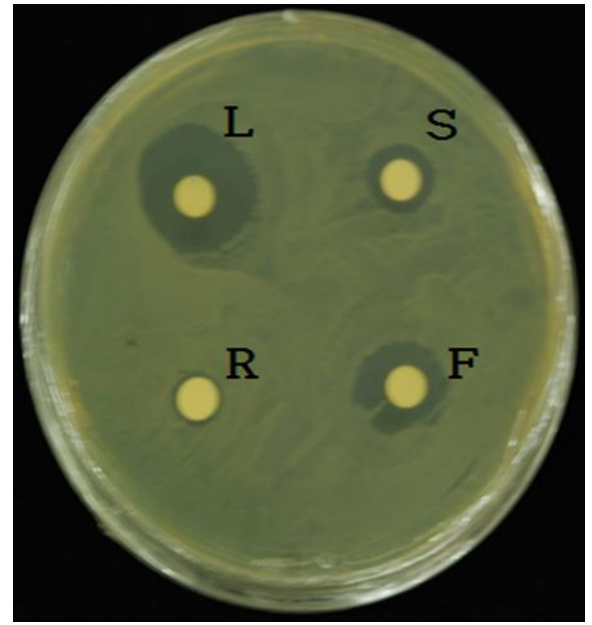

Figure 2. Representative image showing antibacterial activity against a bacterial pathogen. Leaf (L), flower (F), root (R), and stem (S) of Lavandula pubescens.

Table 3. Antibacterial activity of different organs of Lavandula pubescens. Each value is the average of three trials \pm standard deviation.

\begin{tabular}{ccccc}
\hline \multirow{2}{*}{ Strains } & \multicolumn{3}{c}{ Zone of Inhibition $(\mathbf{m m})$} & from L. pubescens Extracts \\
\cline { 2 - 5 } & Flower & Leaf & Stem & Root \\
\hline Escherichia coli (KF 918342) & $17.6 \pm 0.6$ & $22.3 \pm 0.6$ & $15.3 \pm 0.6$ & NA $^{1}$ \\
staphylococcus haemolyticus & $17.6 \pm 0.6$ & $23.0 \pm 1.0$ & $19.0 \pm 1.0$ & NA \\
Aeromonas hydrophila & $14.3 \pm 1.5$ & $16.0 \pm 0.0$ & $13.7 \pm 0.6$ & NA \\
Escherichia coli (ATCC 35150) & $15.3 \pm 0.6$ & $18.0 \pm 1.0$ & $13.0 \pm 0.0$ & NA \\
Cronobacter sakazakii & $13.7 \pm 0.6$ & $21.3 \pm 1.1$ & $13.6 \pm 0.6$ & NA \\
Aeromonas salmonicida & $14.7 \pm 0.6$ & $20.3 \pm 0.6$ & $12.3 \pm 0.6$ & NA \\
\hline \multicolumn{7}{l}{${ }^{1}$ NA, no activity. }
\end{tabular}

\subsection{Minimum Inhibitory Concentration of L. pubescens}

The MIC of crude Lavandula extract was studied by the micro broth dilution method and the results are shown in Table 2. Lavandula ethyl acetate extract at different concentrations inhibited all the growth of all bacterial strain broths. The MIC for E. coli was $6.25 \mu \mathrm{L}$ and for S. haemolyticus, A. hydrophila, and A. salmonicida was $12.5 \mu \mathrm{L}$. Cronobacter sakazakii inhibition was observed at $25 \mu \mathrm{L}$. Streptomycin showed better MIC values in comparison with those of the Lavandula ethyl acetate extracts. MIC values are shown in Table 4.

Table 4. Antibacterial activity of different organs of Lavandula pubescens.

\begin{tabular}{ccc}
\hline \multirow{2}{*}{ Strains } & \multicolumn{2}{c}{ Minimum Inhibitory Concentration (MIC) } \\
\cline { 2 - 3 } & Compound $(\boldsymbol{\mu L})$ & Standard $(\boldsymbol{\mu g})$ \\
\hline Escherichia coli (KF 918342) & 6.25 & 25 \\
Staphylococcus haemolyticus & 12.5 & 50 \\
Aeromonas hydrophila & 12.5 & 50 \\
Escherichia coli (ATCC 35150) & 6.25 & 25 \\
Cronobacter sakazakii & 25 & 100 \\
Aeromonas salmonicida & 12.5 & 50 \\
\hline
\end{tabular}

\section{Discussion}

In this study, 71 volatile compounds were identified in the essential oils derived from the roots, stems, leaves, and flowers of L. pubescens through GC-MS analysis. The most abundant constituents 
were terpenes, including monoterpenes, diterpenes, and sesquiterpenes. Similarly, previous studies have shown that terpene metabolites were the major components of essential oils from a variety of Lavandula species: Barocelli et al. reported a total of 23 constituents in Lavandula hybrida Reverchon "Grosso" essential oil, with major constituents such as linalool (33.4\%), linalyl acetate (36.2\%), camphor (7.6\%), and 1,8-cineole (5.8\%) [29]. Fenchone (55.79\%), camphor (18.18\%), 1,8-cineole (8.03\%), and myrtenyl acetate $(6.25 \%)$ were the major compounds among the 18 identified essential oil constituents of Lavandula stoechas L. (Spanish lavender) [30]. The major constituents in L. angustifolia essential oil were 1,8-cineole (44.9\%), camphor (14.3\%), $\beta$-phellandrene (5.0\%), and $\alpha$-pinene (4.7\%) [31]. Shirugumbi et al. reported that Lavandula bipinnata essential oil had transcarveol $(18.93 \%)$, pulegone $(8.45 \%)$, camphor (7.09\%), and menthol (5.89\%) [32]. Spike lavender (L. latifolia Med.) and lavandin (Lavandula $\times$ intermedia) essential oils contained camphor $(32.70 \%), 1,8$-cineole $(26.9 \%)$, and caryophyllene $(4.88 \%)$ and 1,8-cineol (40.5\%), linalool (33.1\%), and camphor (8.17\%), respectively [33]. Furthermore, Al-Badani et al. reported a total of 26 constituents in essential oil from the aerial parts of L. pubescens, with main components including carvacrol (72.7\%), carvacrol methyl ether $(7.0 \%)$, and caryophyllene oxide $(5.9 \%)[34]$.

Ethyl acetate extract of L. pubescens tested in the present study showed strong antibacterial activity against the six bacterial strains tested. However, antibacterial activities of the extracts dissolved in the other solvents were not observed. This could be caused by the difference in the chemical composition of these extracts. Often, variations in chemical composition may result from differences in the extraction solvents, season, and presence of secondary metabolites [35]. Previous studies have shown that lavender plants contain a broad variety of terpenes, including monoterpenes, sesquiterpenes, and diterpenes, as well as phenolic compounds exhibiting antimicrobial activity [36-38].

Ethyl acetate extracts of $L$. pubescens possessed strong antibacterial activity against the six pathogenic bacteria, and L. pubescens leaves had the most powerful antimicrobial capacity. Our results are supported by those of previous studies showing that the essential oil from Lavandula species had antibacterial properties [39]. Hui et al. reported that lavender essential oil showed anti-bacterial activities against E. coli and Staphylococcus aureus [40]. Hossain reported that the essential oil of L. angustifolia was effective against all tested turtle-borne pathogenic bacteria: A. hydrophila, Aeromonas caviae, and Aeromonas dhakensis [41]. Furthermore, lavender essential oil nanoemulsions showed anti-bacterial activity against C. sakazakii [42]. The essential oil of L. angustifolia showed anti-bacterial activity against S. aureus, E. coli, Citrobacter freundii, Enterobacter aerogenes, Propionibacterium acnes, Proteus vulgaris, Pseudomonas aeruginosa, Shigella sonnei, and Streptococcus pyogenes [43]. Therefore, the essential oils from Lavandula plants are expected to possess important antibacterial properties against various bacterial species.

According to the World Health Organization (WHO), approximately $80 \%$ of the world's population depends on herbal remedies for their primary healthcare $[44,45]$. This study showed the different chemical composition in essential oils of different parts of L. pubescens and the different antibacterial activity of ethyl acetate extracts of these plant parts. These properties could be successfully exploited to treat several diseases caused by bacterial infections. This may indicate that lavender species used in traditional remedies may possess beneficial biological activity. Thus, this study suggests the potential use of L. pubescens roots, stems, leaves, and flowers in traditional herbal medicine applications.

\section{Conclusions}

In this study, ethyl acetate was the most effective solvent for extracting a broad variety of compounds from L. pubescens, and its extract possessed strong antibacterial activity against Escherichia coli (KF 918342), Staphylococcus haemolyticus (KCTC 3341), Aeromonas hydrophila (KCTC 12487), Escherichia coli (ATCC 35150), Cronobacter sakazakii (ATCC 29544), and Aeromonas salmonicida (KACC 15136). In particular, the leaves exhibited the strongest antimicrobial activity against these bacteria among the different plant parts tested. Therefore, this study suggests that L. pubescens could be considered a good source for human health. 
Author Contributions: S.U.P. designed the experiments and analyzed the data. C.H.P., H.J.Y., Y.E.P., S.W.C., and S.S.L. performed the experiments and analyzed the data. C.H.P. and Y.E.P. wrote the manuscript. All authors read and approved the final manuscript.

Acknowledgments: This research was supported by Global PH.D Fellowship Program through the National Research Foundation of Korea (NRF) funded by the Ministry of Education (2017H1A2A1045963).

Conflicts of Interest: The authors declare no conflict of interest.

\section{References}

1. Lis-Balchin, M. Lavender: The Genus Lavandula, 1st ed.; CRC Press: London, UK, 2002; pp. 1-296.

2. Bakkali, F.; Averbeck, S.; Averbeck, D.; Idaomar, M. Biological effects of essential oils-A review. Food Chem. Toxicol. 2008, 46, 446-475. [CrossRef] [PubMed]

3. Djenane, D.; Aïder, M.; Yangüela, J.; Idir, L.; Gómez, D.; Roncalés, P. Antioxidant and antibacterial effects of Lavandula and Mentha essential oils in minced beef inoculated with E. coli O157: H7 and S. aureus during storage at abuse refrigeration temperature. Meat Sci. 2012, 92, 667-674. [CrossRef] [PubMed]

4. An, M.; Haig, T.; Hatfield, P. On-site field sampling and analysis of fragrance from living Lavender (Lavandula angustifolia L.) flowers by solid-phase microextraction coupled to gas chromatography and ion-trap mass spectrometry. J. Chromatogr. 2001, 917, 245-250. [CrossRef]

5. Bicchi, C.; Drigo, S.; Rubiolo, P. Influence of fibre coating in headspace solid-phase microextraction-gas chromatographic analysis of aromatic and medicinal plants. J. Chromatogr. 2000, 892, 469-485. [CrossRef]

6. Kim, N.-S.; Lee, D.-S. Comparison of different extraction methods for the analysis of fragrances from Lavandula species by gas chromatography-mass spectrometry. J. Chromatogr. 2002, 982, 31-47. [CrossRef]

7. Sarker, L.S.; Galata, M.; Demissie, Z.A.; Mahmoud, S.S. Molecular cloning and functional characterization of borneol dehydrogenase from the glandular trichomes of Lavandula x intermedia. Arch. Biochem. Biophys. 2012, 528, 163-170. [CrossRef]

8. Swamy, M.K.; Akhtar, M.S.; Sinniah, U.R. Antimicrobial properties of plant essential oils against human pathogens and their mode of action: An updated review. Evid. Based Complement. Alternat. Med. 2016, 2016, 3012462. [CrossRef] [PubMed]

9. Giarratana, F.; Muscolino, D.; Ziino, G.; Giuffrida, A.; Marotta, S.M.; Presti, V.L.; Chiofalo, V.; Panebianco, A. Activity of Tagetes minuta Linnaeus (Asteraceae) essential oil against L3 Anisakis larvae type 1. Asian Pac. J. Trop. Med. 2017, 10, 461-465. [CrossRef] [PubMed]

10. Giarratana, F.; Muscolino, D.; Ziino, G.; Lo Presti, V.; Rao, R.; Chiofalo, V.; Giuffrida, A.; Panebianco, A. Activity of Catmint (Nepeta cataria) essential oil against Anisakis larvae. Trop. Biomed. 2017, 34, $22-31$.

11. Giarratana, F.; Muscolino, D.; Beninati, C.; Ziino, G.; Giuffrida, A.; Panebianco, A. Activity of R (+) limonene on the maximum growth rate of fish spoilage organisms and related effects on shelf-life prolongation of fresh gilthead sea bream fillets. Int. J. Food Microbiol. 2016, 237, 109-113. [CrossRef] [PubMed]

12. Giarratana, F.; Muscolino, D.; Beninati, C.; Ziino, G.; Giuffrida, A.; Panebianco, A. Effects of thyme and rosemary essential oils on the microbiology and shelf life of Italian Mortadella. Fleischwirtschaft 2013, 93, 183-187.

13. Burt, S. Essential oils: Their antibacterial properties and potential applications in foods-A review. Int. J. Food Microbiol. 2004, 94, 223-253. [CrossRef]

14. Cavanagh, H.M.; Wilkinson, J.M. Lavender essential oil: A review. Aust. Infect. Control 2005, 10, 35-37. [CrossRef]

15. De Castro, M.L.; Jimenez-Carmona, M.; Fernandez-Perez, V. Towards more rational techniques for the isolation of valuable essential oils from plants. TrAC Trends Anal. Chem. 1999, 18, 708-716. [CrossRef]

16. Da Porto, C.; Decorti, D.; Kikic, I. Flavour compounds of Lavandula angustifolia L. to use in food manufacturing: Comparison of three different extraction methods. Food Chem. 2009, 112, 1072-1078. [CrossRef]

17. Parkash, V.; Singh, H. Lavandula angustifolia L. (lavender): An important aromatic medicinal shrub and its in vitro micro-propagation for conservation. J. Agric. Technol. 2013, 9, 91-702.

18. Kageyama, A.; Ueno, T.; Oshio, M.; Masuda, H.; Horiuchi, H.; Yokogoshi, H. Antidepressant-like effects of an aqueous extract of lavender (Lavandula angustifolia Mill.) in rats. Food Sci. Technol. Res 2012, 18, 473-479. [CrossRef] 
19. Koulivand, P.H.; Khaleghi Ghadiri, M.; Gorji, A. Lavender and the nervous system. Evid. Based Complement. Alternat. Med. 2013, 2013, 681304. [CrossRef] [PubMed]

20. Kovatcheva, E.G.; Koleva, I.I.; Ilieva, M.; Pavlov, A.; Mincheva, M.; Konushlieva, M. Antioxidant activity of extracts from Lavandula vera MM cell cultures. Food Chem. 2001, 72, 295-300. [CrossRef]

21. Lis-Balchin, M.; Hart, S. Studies on the mode of action of the essential oil of Lavender Lavandula angustifolia P. Miller. Phytother. Res. 1999, 13, 540-542. [CrossRef]

22. Soltani, R.; Soheilipour, S.; Hajhashemi, V.; Asghari, G.; Bagheri, M.; Molavi, M. Evaluation of the effect of aromatherapy with lavender essential oil on post-tonsillectomy pain in pediatric patients: A randomized controlled trial. Int. J. Pediatr. Otorhinolaryngol. 2013, 77, 1579-1581. [CrossRef]

23. Cavanagh, H.; Wilkinson, J. Biological activities of lavender essential oil. Phytother. Res. 2002, 16, 301-308. [CrossRef]

24. Kashani, M.S.; Tavirani, M.R.; Talaei, S.A.; Salami, M. Aqueous extract of lavender (Lavandula angustifolia) improves the spatial performance of a rat model of Alzheimer's disease. Neurosci. Bull. 2011, 27, 99-106. [CrossRef]

25. Sienkiewicz, M.; Lysakowska, M.; Ciecwierz, J.; Denys, P.; Kowalczyk, E. Antibacterial activity of thyme and lavender essential oils. Med. Chem. 2011, 7, 674-689. [CrossRef]

26. Park, C.H.; Yeo, H.J.; Baskar, T.B.; Park, Y.E.; Park, J.S.; Lee, S.Y.; Park, S.U. In Vitro Antioxidant and Antimicrobial Properties of Flower, Leaf, and Stem Extracts of Korean Mint. Antioxidants 2019, 8, 75. [CrossRef]

27. Lim, S.S.; Jang, J.M.; Park, W.T.; Uddin, M.R.; Chae, S.C.; Kim, H.H.; Park, S.U. Chemical Composition of Essential Oils from Flower and Leaf of Korean Mint, Agastache rugosa. Asian J. Chem. 2013, 25, 4361-4363. [CrossRef]

28. Abdullah Al-Dhabi, N.; Valan Arasu, M.; Rejiniemon, T.S. In vitro antibacterial, antifungal, antibiofilm, antioxidant, and anticancer properties of isosteviol isolated from endangered medicinal plant Pittosporum tetraspermum. Evid. Based Complement. Alternat. Med. 2015, 2015, 164261. [CrossRef]

29. Barocelli, E.; Calcina, F.; Chiavarini, M.; Impicciatore, M.; Bruni, R.; Bianchi, A.; Ballabeni, V. Antinociceptive and gastroprotective effects of inhaled and orally administered Lavandula hybrida Reverchon "Grosso" essential oil. Life Sci. 2004, 76, 213-223. [CrossRef]

30. Dadalioğlu, I.; Evrendilek, G.A. Chemical compositions and antibacterial effects of essential oils of Turkish oregano (Origanum minutiflorum), bay laurel (Laurus nobilis), Spanish lavender (Lavandula stoechas L.), and fennel (Foeniculum vulgare) on common foodborne pathogens. J. Agric. Food Chem. 2004, 52, 8255-8260. [CrossRef]

31. Karamanoli, K.; Vokou, D.; Menkissoglu, U.; Constantinidou, H.-I. Bacterial colonization of phyllosphere of Mediterranean aromatic plants. J. Chem. Ecol. 2000, 26, 2035-2048. [CrossRef]

32. Hanamanthagouda, M.S.; Kakkalameli, S.B.; Naik, P.M.; Nagella, P.; Seetharamareddy, H.R.; Murthy, H.N. Essential oils of Lavandula bipinnata and their antimicrobial activities. Food Chem. 2010, 118, 836-839. [CrossRef]

33. Jianu, C.; Pop, G.; TGruia, A.; Horhat, F.G. Chemical composition and antimicrobial activity of essential oils of lavender (Lavandula angustifolia) and lavandin (Lavandula $\times$ intermedia) grown in Western Romania. Int. J. Agric. Biol. 2013, 15, 772-776.

34. Al-Badani, R.N.; da Silva, J.K.R.; Mansi, I.; Muharam, B.A.; Setzer, W.N.; Awadh Ali, N.A. Chemical composition and biological activity of Lavandula pubescens essential oil from Yemen. J. Essent. Oil. Bear. Plants 2017, 20, 509-515. [CrossRef]

35. Thaker, A.; ANJARIA, J. Antimicrobial and infected wound healing response of some traditional drugs. Indian J. Pharmacol. 1986, 18, 171-174.

36. Costa, P.; Gonçalves, S.; Valentão, P.; Andrade, P.B.; Almeida, C.; Nogueira, J.M.; Romano, A. Metabolic profile and biological activities of Lavandula pedunculata subsp. lusitanica (Chaytor) Franco: Studies on the essential oil and polar extracts. Food Chem. 2013, 141, 2501-2506. [CrossRef]

37. Zuzarte, M.; Gonçalves, M.; Cruz, M.; Cavaleiro, C.; Canhoto, J.; Vaz, S.; Pinto, E.; Salgueiro, L. Lavandula luisieri essential oil as a source of antifungal drugs. Food Chem. 2012, 135, 1505-1510. [CrossRef]

38. Sienkiewicz, M.; Głowacka, A.; Kowalczyk, E.; Wiktorowska-Owczarek, A.; Jóźwiak-Bębenista, M.; ysakowska, M. The biological activities of cinnamon, geranium and lavender essential oils. Molecules 2014, 19, 20929-20940. [CrossRef] 
39. Cherrat, L.; Espina, L.; Bakkali, M.; Pagán, R.; Laglaoui, A. Chemical composition, antioxidant and antimicrobial properties of Mentha pulegium, Lavandula stoechas and Satureja calamintha Scheele essential oils and an evaluation of their bactericidal effect in combined processes. Innov. Food Sci. Emerg. Technol. 2014, 22, 221-229. [CrossRef]

40. Hui, L.; He, L.; Huan, L.; XiaoLan, L.; AiGuo, Z. Chemical composition of lavender essential oil and its antioxidant activity and inhibition against rhinitis-related bacteria. Afr. J. Microbiol. Res. 2010, 4, 309-313.

41. Hossain, S.; Heo, H.; De Silva, B.; Wimalasena, S.; Pathirana, H.; Heo, G.-J. Antibacterial activity of essential oil from lavender (Lavandula angustifolia) against pet turtle-borne pathogenic bacteria. Lab. Anim. Res. 2017, 33, 195-201. [CrossRef]

42. Kim, M.S.; Lee, K.W.; Park, E.J. Antimicrobial Activity of Lavander and Rosemary Essential Oil Nanoemulsions. Korean J. Food Cook. Sci. 2017, 33, 256-263. [CrossRef]

43. Moon, T.; Wilkinson, J.; Cavanagh, H. Antibacterial activity of essential oils, hydrosols and plant extracts from Australian grown Lavandula spp. Int. J. Aromather. 2006, 16, 9-14. [CrossRef]

44. Akerele, O. Nature's medicinal bounty: Don't throw it away. World Health Forum 1993, 14, 390-395. [PubMed]

45. Ekor, M. The growing use of herbal medicines: Issues relating to adverse reactions and challenges in monitoring safety. Front. Pharmacol. 2014, 4, 177. [CrossRef] [PubMed]

(C) 2019 by the authors. Licensee MDPI, Basel, Switzerland. This article is an open access article distributed under the terms and conditions of the Creative Commons Attribution (CC BY) license (http://creativecommons.org/licenses/by/4.0/). 